\title{
Blood plasma traits associated with genetic merit for feed utilization in Holstein cows
}

\author{
C. D. Dechow, ${ }^{* 1}$ C. R. Baumrucker, ${ }^{*}$ R. M. Bruckmaier, $\dagger$ and J. W. Blum ${ }^{*} \dagger^{2}$ \\ *Department of Dairy and Animal Science, Penn State University, 324 Henning Bldg., University Park 16801 \\ †Veterinary Physiology, Vetsuisse Faculty, University of Bern, Bremgartenstrasse 109a, 3012 Bern, Switzerland
}

\begin{abstract}
The objective of this study was to evaluate the potential of selection for feed utilization on associated blood plasma metabolite and hormone traits. Dry matter intake (DMI) was recorded in 970 Holsteins from 11 commercial farms in Pennsylvania and used to derive dry matter efficiency (DME; fat-corrected milk yield/ $\mathrm{DMI}$ ), crude protein efficiency (CPE; protein yield/ crude protein intake), and residual feed intake (RFI, defined as actual feed intake minus expected feed intake for maintenance and milk production, based on calculation of DMI adjusted for yield, body weight, and body condition score). Estimated breeding values for the 4 feed utilization traits (DMI, DME, CPE, and RFI), yield traits, body traits, and days open were standardized according to their respective genetic standard deviations. Up to 631 blood samples from 393 cows from 0 to $60 \mathrm{~d}$ in milk (DIM) were evaluated for blood plasma concentrations of glucose, nonesterified fatty acids (NEFA), $\beta$-hydroxybutyrate (BHB), creatinine, urea, growth hormone $(\mathrm{GH}), 3,5,3^{\prime}$-triiodothyronine (T3), and other parameters. Blood plasma traits were regressed on DIM, lactation number, herd, and standardized genetic merit. Cows with higher genetic merit for yield had significantly higher concentrations of GH, NEFA (milk and protein yield), and BHB (fat yield) from 31 to 60 DIM, but lower concentrations of glucose from 0 to 30 DIM, and T3 (milk yield, 0-60 DIM). The high GH-low glucose-low T3 concentration pattern was further accentuated for cows with genetic merit for enhanced feed efficiency (higher DME and lower RFI). Cows with a genetic tendency to be thin (low body condition score) also had elevated GH concentrations, but lower blood glucose, creatinine, and T3 concentrations. Those characteristics associated with enhanced feed efficiency (higher GH and lower glucose and T3
\end{abstract}

Received December 21, 2016.

Accepted June 4, 2017.

${ }^{1}$ Corresponding author: cdd1@psu.edu

${ }^{2}$ Present address: Scheuermattweg 45, 3043 Uettligen, Switzerland. concentrations) were unfavorably associated with fertility, as indicated by elevated days open. Elevated NEFA and BHB concentrations were also associated with extended days open. Consideration of metabolic profiles when evaluating feed efficiency might be a method of maintaining high levels of health and reproductive fitness when selecting for feed efficiency.

Key words: feed efficiency, residual feed intake, metabolite, hormone

\section{INTRODUCTION}

Selection for yield has increased milk production by $3,713 \mathrm{~kg}$ in the United States since 1960 (https:// www.cdcb.us/eval/summary/trend.cfm). Studies of the genetic relationship of yield with metabolites and hormones in blood and milk have helped researchers more fully appreciate the effects of selection for yield on physiological processes in the cow (for a review, see Veerkamp et al., 2003). In some studies, blood traits were measured in young bulls and heifers with the aim of developing early-life predictors of genetic merit (Hayhurst et al., 2009) or as targets of selection in instances where routine milk recording is not practiced (Peterson et al., 1982); however, such efforts did not materialize and are no longer considered necessary because genomic selection can provide early-life prediction of genetic merit with high accuracy (VanRaden et al., 2009). Recent advances in the evaluation of milk samples (Wittenburg et al., 2013) have also created opportunities to evaluate the potential of selection on metabolites to improve the nutritional composition of milk for humans and to improve cow health and reproductive performance (Koeck et al., 2014).

Selection for milk yield has greatly enhanced the efficiency of feed utilization through dilution of maintenance nutrient requirements (Capper et al., 2009). However, genetic selection programs are increasingly focused on direct selection for feed efficiency by developing predictions for DMI (de Haas et al., 2015) and residual feed intake (RFI; Pryce et al., 2015). Insulin signaling and lipid metabolism have been as- 
Table 1. The number of observations (n), mean and standard deviation (SD) for blood metabolites from DIM 0 to 30 and from DIM 31 to 60

\begin{tabular}{|c|c|c|c|c|c|c|}
\hline \multirow[b]{2}{*}{ Metabolite $^{1}$} & \multicolumn{3}{|c|}{0 to 30 DIM } & \multicolumn{3}{|c|}{31 to $60 \mathrm{DIM}$} \\
\hline & $\mathrm{n}$ & Mean & $\mathrm{SD}$ & $\mathrm{n}$ & Mean & SD \\
\hline Glucose $(\mathrm{mmol} / \mathrm{L})$ & 316 & 3.529 & 0.504 & 315 & 3.694 & 0.405 \\
\hline NEFA $(\mathrm{mmol} / \mathrm{L})$ & 301 & 0.665 & 0.361 & 306 & 0.399 & 0.229 \\
\hline ln NEFA & 301 & -0.554 & 0.560 & 306 & -1.088 & 0.604 \\
\hline $\mathrm{BHB}(\mathrm{mmol} / \mathrm{L})$ & 316 & 0.827 & 0.764 & 315 & 0.651 & 0.783 \\
\hline $\ln \mathrm{BHB}$ & 316 & -0.449 & 0.661 & 315 & -0.715 & 0.638 \\
\hline Growth hormone $(\mu \mathrm{g} / \mathrm{L})$ & 178 & 8.248 & 4.440 & 115 & 7.370 & 3.884 \\
\hline T3 (triiodothyronine) $(\mathrm{nmol} / \mathrm{L})$ & 178 & 1.227 & 0.529 & 116 & 1.358 & 0.439 \\
\hline Creatinine $(\mu \mathrm{mol} / \mathrm{L})$ & 138 & 99.732 & 14.059 & 199 & 87.980 & 9.980 \\
\hline Urea $(\mathrm{mmol} / \mathrm{L})$ & 316 & 4.170 & 1.406 & 315 & 4.191 & 1.313 \\
\hline
\end{tabular}

${ }^{1} \ln \mathrm{NEFA}=$ natural $\log$ of nonesterified fatty acids; ln BHB = natural log of BHB.

sociated with differences in RFI for lactating cattle (Xi et al., 2015). However, relationships of feed efficiency with blood metabolites and hormones have not been defined as clearly as relationships of milk yield with blood metabolites and hormones. The objective of this study was to investigate relationships of feed utilization and related traits with blood metabolite and hormone profiles in early lactating Holsteins.

\section{MATERIALS AND METHODS}

\section{Feeding and Feed Intake}

Feed intake measures and genetic evaluation of feed utilization have been described previously for this population of lactating Holstein cows (Vallimont et al., 2010, 2011, 2013). Briefly, feed intake was measured over a 24-h period for 970 cows from 11 commercial tiestall herds in Pennsylvania. Herds were visited once a month over a period of 6 mo during the week of monthly milk sampling. The feed intake measures were used to derive 305-d feed intake prediction as well as other feed utilization traits, including DM efficiency (DME; FCM yield/DMI); CP efficiency (CPE; protein yield/CP intake); and RFI (DMI adjusted for yield, BW, and BCS).

\section{Blood Samples}

Blood samples $(20 \mathrm{~mL})$ from cows with feed intake measured during their first 2 test dates and that were $\leq 60$ DIM were obtained from the tail vein using evacuated tubes containing EDTA $(1.8 \mathrm{~g} / \mathrm{L}$ of blood) for DNA marker analysis (Dekleva et al., 2012; Dechow and Haagen, 2014) and for evaluation of metabolites, hormones, and aspartate aminotransferase (AST). Tubes were immediately cooled on ice and then centrifuged at $1,500 \times g$ for $20 \mathrm{~min}$; the supernatants (plasma) were stored in multiple aliquots at $-20^{\circ} \mathrm{C}$ until analyzed.
Concentrations of glucose, nonesterified fatty acids (NEFA), triglycerides, cholesterol, creatinine, urea, BHB, growth hormone (GH), 3,5,3'-triiodothyronine (T3), and activities of AST were determined at the Vetsuisse Faculty at the University of Bern. Hormone concentrations were determined by radioimmunoassay and the other traits were determined using kits as previously described (Aeberhard et al., 2001; Reist et al., 2003). An initial batch of 294 samples was evaluated for glucose, NEFA, BHB, cholesterol, urea, GH, T3, and triglycerides in July 2010, and a second batch of 337 samples was evaluated for glucose, NEFA, BHB, cholesterol, urea, creatinine, and AST in October 2011. There were 238 cows included in both sample periods and 155 cows included in a single sample period. The number of observations, means, and standard deviations for the principal blood traits considered (glucose, NEFA, BHB, cholesterol, urea, GH, T3, creatinine) are reported in Table 1.

\section{Statistical Analysis}

Estimated breeding values for selected traits were extracted from the previous genetic evaluations (Vallimont et al., 2010, 2011, 2013) that were conducted with ASREML (Gilmour et al., 2009). The yield traits considered were milk, fat, and protein yields; the feed utilization traits were DMI, DME, CPE, and RFI; and additional traits were BW, BCS, MUN, and days open. To compare results more directly across traits, all EBV were standardized to a mean of 0 and standard deviation of 1. Mean reliabilities for EBV were lowest for days open (35\%), BCS (45\%), and RFI (50\%); all other reliabilities ranged from $61 \%$ (DMI) to $79 \%$ (MUN).

The relationship of the blood traits with genetic merit was evaluated using a series of regression models in SAS (v 9.3; SAS Institute Inc., Cary, NC). An initial evaluation determined the relationship of herd, DIM, $\operatorname{DIM}^{2}$, and lactation $(1,2, \geq 3)$ for all blood traits and 
included in further analyses if significant $(P<0.05)$ for that particular blood trait. A natural logarithm transformation was applied to NEFA (ln NEFA) and BHB (ln BHB) concentrations before regression because both had a right-skewed distribution. A random effect for cow was tested for all traits and included in the analysis if the Akaike information criterion-corrected was improved (glucose, creatinine, ln BHB, ln NEFA, AST, urea). Standardized EBV was included as a covariate for each analysis. Including a random cow effect with regression on EBV is similar to a traditional genetic evaluation that includes permanent environment and additive genetic effects. Excluding the random cow effect had minimal effect on the genetic regression estimates. A second series of analyses was conducted with DIM 0 to 30 considered separately from DIM 31 to 60 . The procedure was the same as above, except that no cows had multiple records so that the random cow effect was not considered. A genetic regression was implemented because our data set was too small to provide meaningful estimates of heritability and genetic correlations with reasonable precision.

\section{RESULTS AND DISCUSSION}

\section{Blood Plasma Traits}

Mean values for all traits from 0 to $30 \mathrm{DIM}$ and 31 to 60 DIM are reported in Table 1 and were in the range reported for early lactation dairy cows (Aeberhard et al., 2001; Reist et al., 2003). Samples were taken in early lactation and before recombinant (r)bST can legally be administered, so GH measurements were not influenced by exogenous rbST treatment. As expected, indicators of negative energy balance (NEFA and BHB) were higher from 0 to 30 DIM than from 31 to 60 DIM, whereas glucose concentration was higher from 31 to 60 DIM than from 0 to 30 DIM.

\section{Feed Utilization}

Coefficients for the regression of blood traits on genetic merit for the primary traits of interest are reported in Table 2. These and coefficients for an expanded list of secondary traits and blood parameters that were not directly related to feed efficiency are available in Supplemental Table S1 (https://doi.org/10.3168/jds.2016 -12502). Surprisingly, genetic merit for DMI was not significantly associated with any of the blood plasma traits. The decrease in DMI that often occurs before parturition is associated with a decline in blood glucose levels and an increase in NEFA concentrations (Kunz et al., 1985; Ingvartsen and Andersen, 2000). Thus, one might hypothesize that higher genetic merit for DMI would be associated with increased blood glucose levels but this was not observed. The genetic correlation between DMI and milk yield was previously reported to be 0.51 for this population (Vallimont et al., 2010), so it is possible that the additional energy intake of cows with high genetic merit for DMI was simply used to support milk production.

Relationships of gross feed efficiency (DME and $\mathrm{CPE}$ ) with blood traits were generally similar to those reported between yield and blood traits but to a larger magnitude in some instances. Growth hormone concentration increased by $1.512 \mu \mathrm{g} / \mathrm{L}$ per genetic standard deviation of DME, which was larger than the increase observed for yield traits $(0.952$ to $1.356 \mu \mathrm{g} / \mathrm{L})$. Glucose concentrations decreased more strongly with increasing higher genetic merit for DME than for yield, with the negative relationship extended through the 31 to 60 DIM window (Table 3), which was not true for

Table 2. Regression of blood metabolites ${ }^{1}$ on standardized genetic merit

\begin{tabular}{lccccrrr}
\hline Trait $^{2}$ & Glucose & ln NEFA & ln BHB & GH & T3 & Creat & Urea \\
\hline DMI & -0.006 & 0.012 & 0.033 & 0.247 & -0.002 & 0.302 & -0.045 \\
DME & $-0.061^{*}$ & 0.034 & $0.070 \dagger$ & $1.512^{*}$ & $-0.065^{*}$ & -0.304 & -0.001 \\
RFI & $0.082^{*}$ & -0.034 & -0.052 & $-2.334^{*}$ & $0.083 \dagger$ & 1.727 & $-0.177 \dagger$ \\
CPE & -0.033 & 0.029 & -0.001 & $1.093^{*}$ & $-0.059^{*}$ & -0.213 & -0.008 \\
Milk & -0.041 & $0.085^{*}$ & 0.017 & $0.952^{*}$ & $-0.079^{*}$ & -0.368 & 0.057 \\
Fat & $-0.047 \dagger$ & -0.008 & $0.072 \dagger$ & $1.356^{*}$ & -0.020 & -0.102 & -0.039 \\
Protein & -0.026 & 0.032 & -0.013 & $1.083^{*}$ & $-0.054 \dagger$ & -0.116 & -0.014 \\
BW & 0.031 & 0.006 & -0.012 & $-0.986^{*}$ & 0.024 & 0.932 & -0.059 \\
BCS & $0.073^{*}$ & 0.004 & 0.021 & $-2.598^{*}$ & $0.142^{*}$ & $4.328^{*}$ & $-0.141 \dagger$ \\
MUN & -0.020 & 0.019 & -0.008 & 0.717 & 0.015 & $2.652^{*}$ & $0.483^{*}$ \\
DO & $-0.087^{*}$ & $0.098^{*}$ & 0.077 & $1.720^{*}$ & $-0.111^{*}$ & 0.414 & 0.029 \\
\hline
\end{tabular}

${ }^{1} \ln$ NEFA = natural log of nonesterified fatty acids; ln BHB = natural log of BHB; GH = growth hormone; T3 $=$ triiodothyronine; Creat $=$ creatinine.

${ }^{2} \mathrm{DME}=\mathrm{DM}$ efficiency; RFI $=$ residual feed intake; $\mathrm{CPE}=\mathrm{CP}$ efficiency; Milk = milk yield; Fat $=$ fat yield; Protein $=$ protein yield; $\mathrm{DO}=$ days open .

$* P<0.05 ; \dagger P<0.10$. 
Table 3. The regression of selected blood metabolites ${ }^{1}$ from 0 to 30 DIM and from 31 to 60 DIM on standardized genetic merit

\begin{tabular}{|c|c|c|c|c|c|c|}
\hline \multirow[b]{2}{*}{ Trait $^{2}$} & \multicolumn{3}{|c|}{0 to 30 DIM } & \multicolumn{3}{|c|}{31 to $60 \mathrm{DIM}$} \\
\hline & Glucose & ln NEFA & $\ln \mathrm{BHB}$ & Glucose & ln NEFA & $\ln \mathrm{BHB}$ \\
\hline DME & $-0.127^{*}$ & 0.010 & 0.074 & $-0.062^{*}$ & $0.100^{*}$ & $0.117^{*}$ \\
\hline RFI & $0.150^{*}$ & -0.034 & -0.058 & $0.082^{*}$ & 0.014 & -0.015 \\
\hline CPE & $-0.089^{*}$ & 0.010 & 0.041 & -0.036 & $0.133^{*}$ & 0.039 \\
\hline Milk & $-0.081^{*}$ & $0.071 \dagger$ & 0.038 & -0.044 & $0.170^{*}$ & 0.048 \\
\hline Fat & $-0.103^{*}$ & -0.038 & 0.071 & -0.040 & 0.020 & $0.110^{*}$ \\
\hline Protein & $-0.082^{*}$ & 0.009 & 0.038 & -0.024 & $0.139 *$ & 0.027 \\
\hline DO & $-0.168^{*}$ & $0.084 \dagger$ & 0.090 & $-0.087^{*}$ & $0.162^{*}$ & $0.132^{*}$ \\
\hline
\end{tabular}

${ }^{1} \ln$ NEFA = natural log of nonesterified fatty acids; ln BHB = natural log of BHB.

${ }^{2} \mathrm{DME}=\mathrm{DM}$ efficiency; RFI = residual feed intake $\mathrm{CPE}=\mathrm{CP}$ efficiency; Milk = milk yield; Fat $=$ fat yield; Protein $=$ protein yield; $\mathrm{DO}=$ days open .

$* P<0.05 ; \dagger P<0.10$.

yield. Selection for DME was unfavorably associated with indicators of negative energy balance (NEFA and BHB) from 31 to 60 DIM, in agreement with previous observations that high DME was associated with greater BCS loss in early lactation in this population (Vallimont et al., 2011).

Of the yield and feed utilization traits, RFI had the numerically strongest (positive) relationship with glucose concentrations, with low efficiency (i.e., high RFI) being associated with significantly higher blood glucose concentrations. This observation is supported by reported relationships between RFI and energy balance. Residual feed intake and energy balance are conceptually similar because RFI is derived as the difference between actual DMI and estimated DMI using regression coefficients on energy sinks estimated with the actual data, whereas energy balance is the difference between energy intake and energy expenditure (Savietto et al., 2014). The genetic correlation between RFI and energy balance was reported to be 0.85 in Irish dairy cattle (McParland et al., 2014). Cows with higher blood glucose levels have higher energy balance (Buckley et al., 2000) so our results support the observation that selection for RFI would lower energy balance. This does not mean that selection for lower RFI would create negative energy balance, per se, as RFI derivations account for body tissue mobilization, but it would likely result in less positive energy balance.

Genetic merit for RFI in the current study also had a strong (negative) relationship with GH concentration $(-2.334 \mu \mathrm{g} / \mathrm{L})$. Exogenous GH administration increases DMI but also preferentially partitions nutrients toward yield, resulting in enhanced DME (Bauman 1992). Here, GH was strongly associated with higher yield but not DMI. Cows with high GH thus had high yield independent of DMI, resulting in less feed intake than that predicted based on milk, fat, and protein yields.
We detected a tendency toward lower BUN concentrations as genetic merit for RFI increased. This corresponds to observations by Rius et al. (2012) that demonstrated higher MUN concentrations for cows selected for low RFI. Low RFI cows also partitioned a smaller proportion of dietary $\mathrm{N}$ to casein than did high RFI cows (Rius et al., 2012). Blood urea-N concentration in cattle is well known to depend markedly (although not exclusively) on the amount of ingested $\mathrm{CP}$ and its microbial degradability and resynthesis in the rumen, which is a function of energy intake and energy-to-CP ratio. An insufficient intake of energy thus leads to increased plasma concentrations of urea$\mathrm{N}$ and urea- $\mathrm{N}$ losses through milk (as indicated by the strong relationship between MUN and BUN levels in Table 2) and urine. The inverse relationship between $\mathrm{RFI}$ and urea-N may indicate that energy intake was not sufficient in the low RFI animals to utilize $\mathrm{N}$ as effectively in lactating cows, but this relationship was not noted in growing beef heifers (Kelly et al., 2010).

Gross feed efficiency (DME and CPE) was associated with a reduction in T3 concentrations, and there was a trend for more efficient RFI (i.e., lower RFI) to correspond with lower (but not abnormally low) T3 concentration. Plasma T3, which is mainly derived from deiodination of thyroxine (T4) in the liver, stimulates body heat production and thus contributes to energy losses (Silva, 2001). Importantly, plasma T3 concentrations mirror energy (and N) balances, as shown in sheep (Blum et al., 1980). In accordance, negative energy balances in dairy cows in early lactation are associated with relatively low plasma T3 levels (Blum et al., 1983; Kunz et al., 1985; Reist et al., 2003), indicating that dairy cows, by means of decreased whole-body T3 production, reduce heat and thus reduce this source of energy losses. This results in the sparing of energy for milk production, enhancing energy utilization. 


\section{Milk, Fat, and Protein Yields}

Higher genetic merit for milk yield was significantly associated with higher NEFA concentrations from 0 to $60 \mathrm{~d}$ in the current study, whereas higher genetic merit for fat yield tended to be associated with higher BHB levels. The association of yield with NEFA and BHB concentrations was more evident when contrasting regression results from 0 to 30 DIM than with those from 31 to 60 DIM, as shown in Table 3. Higher NEFA concentrations from 31 to 60 DIM were significantly associated with increased genetic merit for milk and protein yields, but the relationship was surprisingly not significant from 0 to 30 DIM. This may reflect the fact that almost all cows were in negative energy balance early in lactation, but that cows with high genetic merit for yield have an extended negative energy balance. Higher genetic merit for fat yield was not associated with NEFA concentrations, but was associated with elevated BHB concentrations from 31 to 60 DIM. Milk fatty acids are mainly provided from de novo intramammary synthesis (originating from acetate and, to a lesser extent, from butyrate via BHB) and in early lactation from uptake of plasma NEFA and incorporation thereof into milk fat (Palmquist et al., 1969; Adewuyi et al., 2005). Thus, elevated BHB concentrations may have facilitated higher fat production.

A decrease in blood glucose concentration is known to occur in early lactating dairy cows (Blum et al., 1983; Kunz et al., 1985; Reist et al., 2003) as a consequence of insufficient energy intake and specifically of glucose precursors relative to energy losses through milk, and through an inhibited gluconeogenesis by elevated BHB (Zarrin et al., 2013). Increased genetic merit for milk, fat, and protein yields in this study was significantly associated with lower glucose concentrations from 0 to 30 DIM, but not from 31 to 60 DIM. Other studies have noted lowered blood glucose concentrations in response to selection for yield, especially in early lactation (Veerkamp et al., 2003). Uptake of blood glucose by the mammary gland is a prerequisite for lactose synthesis that determines milk yield. Thus, lowered blood glucose concentration in response to selection for yield indicates that the enhanced use of glucose is in favor of milk production but not in favor of glucose homeostasis, the goal of which is to maintain euglycemia.

Higher genetic merit for milk yield was significantly associated with a decrease in T3 concentration, and we detected a similar trend for T3 with higher genetic merit for protein yield. Enhanced metabolic activity of the mammary gland in association with enhanced synthesis for milk products appears to be facilitated by normal or enhanced intramammary T3 formation from T4; that is, a euthyroid condition in the mammary gland despite energy deficiency, thus enhancing the metabolic priority of the mammary gland (Kahl et al., 1995; Slebodziński et al., 1999).

\section{Body Traits}

Higher genetic merit for BCS was associated with higher blood glucose and lower GH concentrations in the current study, reflecting that less glucose was partitioned toward milk production. A positive correlation between EBV for BCS and blood glucose concentrations has been reported previously (Oikonomou et al., 2008b). Higher genetic merit for BCS was also associated with higher concentrations of T3. This corresponds to observations where BCS, glucose, and T3 concentrations increased when concentrate feeding was increased (Reist et al., 2003), although dietary treatments resulting in a phenotypic effect may not reflect underlying genetic relationships.

Creatinine can be taken as a measure of muscle or lean body mass under conditions of normal kidney functions because nearly all creatine, the precursor of creatinine, is found in skeletal muscle tissue. Creatine diffuses from muscle tissues at a relatively constant rate into blood and is nonenzymatically converted at a constant daily rate to creatinine. Thus, the amount of creatinine production, blood plasma concentration (to some extent), and particularly urinary excretion of creatinine, are correlated with body muscle mass (Heymsfield et al., 1983; Baxmann et al., 2008). Therefore, the positive association of genetic merit for BCS with creatinine concentration might have mirrored the relatively low muscle mass (thin) cows.

\section{Fertility}

Energy deficiency, and thus a lack of metabolic fuel, in response to genetic selection for milk is a well-known cause of reduced fertility (Veerkamp et al., 2003), which is supported by our results. Thus, genetic merit for elevated days open (poorer fertility) in the current study was associated with lower blood glucose concentrations and greater negative energy balance, as indicated by higher NEFA and BHB concentrations, particularly from 31 to 60 DIM (Table 3). These results are similar to the genetic associations reported by Oikonomou et al. (2008a). Insufficient energy intake of cows in early lactation is characterized by low plasma concentrations of glucose and increased plasma concentrations of NEFA and GH (Kunz et al., 1985; Reist et al., 2003), which appears to be more severe in cows with poor genetic merit for fertility. 


\section{CONCLUSIONS}

The results of this study indicate that more direct selection for gross feed efficiency or lower RFI might accelerate nutrient partitioning toward production and subsequently result in lower blood glucose levels, which could compromise fertility. However, the current study was focused on blood plasma traits in early lactation and it is unclear whether the same relationships are maintained in later lactation. Addition of blood metabolites, hormones, and enzyme activity measures from genomic reference populations into total merit selection indices could help maintain high levels of health and reproductive fitness when selecting for feed efficiency. As an alternative to inclusion in selection programs, periodic evaluation of the effects of selection on blood hormones and metabolites will help to establish whether selection is likely to have unfavorable effects on important physiological functioning.

\section{ACKNOWLEDGMENTS}

This research was supported by the Cooperative State Research, Education, and Extension Service (USDA, Washington, DC; CSREES-2008-34437-19335). The authors gratefully acknowledge the generosity of the 11 farms that participated in the trial.

\section{REFERENCES}

Adewuyi, A. A., E. Gruysi, and F. J. C. M. van Eerdenburg. 2005. Non esterified fatty acids (NEFA) in dairy cattle. A review. Vet. Q. 27:117-126.

Aeberhard, K., R. M. Bruckmaier, and J. W. Blum. 2001. Metabolic, enzymatic and endocrine status in high-yielding dairy cows. J. Vet. Med. A Physiol. Pathol. Clin. Med. 48:111-127.

Bauman, D. E. 1992. Bovine somatotropin: Review of an emerging animal technology. J. Dairy Sci. 75:3432-3451.

Baxmann, A. C., M. S. Ahmed, N. C. Marques, V. B. Menon, A. B. Pereira, G. M. Kirsztajn, and I. P. Heilberg. 2008. Influence of muscle mass and physical activity on serum and urinary creatinine and serum cystatin C. Clin. J. Am. Soc. Nephrol. 3:348-354.

Blum, J. W., M. Gingins, P. Vitins, and H. Bickel. 1980. Thyroid hormone levels related to energy and nitrogen balance during weight loss and regain in adult sheep. Acta Endocrinol. (Copenh.) 93:440-447.

Blum, J. W., P. Kunz, H. Leuenberger, K. Gautschi, and M. Keller. 1983. Thyroid hormones, blood plasma metabolites and haematological parameters in relationship to milk yield in dairy cows. Anim. Prod. 36:93-104.

Buckley, F., P. Dillon, M. Rath, and R. F. Veerkamp. 2000. The relationship between genetic merit for yield and live weight, condition score, and energy balance of spring calving Holstein Friesian dairy cows on grass based systems of milk production. J. Dairy Sci. $83: 1878-1886$

Capper, J. L., R. A. Cady, and D. E. Bauman. 2009. The environmental impact of dairy production: 1944 compared with 2007. J. Anim. Sci. 87:2160-2167.

de Haas, Y., J. E. Pryce, M. P. Calus, E. Wall, D. P. Berry, P. Løvendahl, N. Krattenmacher, F. Miglior, K. Weigel, D. Spurlock, K. A. Macdonald, B. Hulsegge, and R. F. Veerkamp. 2015. Genomic prediction of dry matter intake in dairy cattle from an international data set consisting of research herds in Europe, North America, and Australasia. J. Dairy Sci. 98:6522-6534.

Dechow, C. D., and I. Haagen. 2014. Genomic predictions of feed utilization and associations with milk yield, body weight and activity levels in an independent population of Holsteins. 10th World Congress on Genetics Applied to Livestock Production, Vancouver, BC, Canada. Accessed Jul. 17, 2017. https://asas.org/docs/ default-source/wcgalp-posters/848_paper_10000_manuscript 1153_0.pdf?sfvrsn=2.

Dekleva, M. W., C. D. Dechow, J. M. Daubert, W. S. Liu, G. A. Varga, S. Bauck, and B. W. Woodward. 2012. Short communication: Interactions of milk, fat, and protein yield genotypes with herd feeding characteristics. J. Dairy Sci. 95:1559-1564.

Gilmour, A. R., B. J. Gogel, B. R. Cullis, and R. Thompson. 2009. ASReml User Guide Release 3.0. VSN International Ltd., Hemel Hempstead, UK. www.vsni.co.uk.

Hayhurst, C., A. P. Flint, P. Løvendahl, J. A. Woolliams, and M. D. Royal. 2009. Genetic variation of metabolite and hormone concentration in UK Holstein-Friesian calves and the genetic relationship with economically important traits. J. Dairy Sci. 92:4001-4007.

Heymsfield, S. B., C. Arteaga, C. McManus, C. Smith, and S. Moffirt. 1983. Measurement of muscle mass in humans: Validity of the 24hour urinary creatinine method. Am. J. Clin. Nutr. 37:478-494.

Ingvartsen, K. L., and J. B. Andersen. 2000. Integration of metabolism and intake regulation: A review focusing on periparturient animals. J. Dairy Sci. 83:1573-1597.

Kahl, S., A. V. Capuco, M. Binelli, W. K. Vanderkooi, H. A. Tucker, and W. M. Moseley. 1995. Comparison of growth hormone-releasing factor and somatotropin: Thyroid status of lactating, primiparous cows. J. Dairy Sci. 78:2150-2158.

Kelly, A. K., M. McGee, D. H. Crews Jr., T. Sweeney, T. M. Boland, and D. A. Kenny. 2010. Repeatability of feed efficiency, carcass ultrasound, feeding behavior, and blood metabolic variables in finishing heifers divergently selected for residual feed intake. J. Anim. Sci. 88:3214-3225.

Koeck, A., J. Jamrozik, F. S. Schenkel, R. K. Moore, D. M. Lefebvre, D. F. Kelton, and F. Miglior. 2014. Genetic analysis of milk $\beta$-hydroxybutyrate and its association with fat-to-protein ratio, body condition score, clinical ketosis, and displaced abomasum in early first lactation of Canadian Holsteins. J. Dairy Sci. 97:72867292 .

Kunz, P. L., J. W. Blum, I. C. Hart, H. Bickel, and J. Landis. 1985. Effects of different energy intakes before and after calving on food intake, performance and metabolic variables in dairy cows. Anim. Prod. 40:219-231.

McParland, S., E. Lewis, E. Kennedy, S. G. Moore, B. McCarthy, M. O'Donovan, S. T. Butler, J. E. Pryce, and D. P. Berry. 2014. Mid-infrared spectrometry of milk as a predictor of energy intake and efficiency in lactating dairy cows. J. Dairy Sci. 97:5863-5871.

Oikonomou, G., G. Arsenos, G. E. Valergakis, A. Tsiaras, D. Zygoyiannis, and G. Banos. 2008a. Genetic relationship of body energy and blood metabolites with reproduction in Holstein cows. J. Dairy Sci. 91:4323-4332.

Oikonomou, G., G. E. Valergakis, G. Arsenos, N. Roubies, and G. Banos. 2008b. Genetic profile of body energy and blood metabolic traits across lactation in primiparous Holstein cows. J. Dairy Sci. 91:2814-2822.

Palmquist, D. L., C. L. Davis, R. E. Brown, and D. S. Sachan. 1969. Availability and metabolism of various substrates in ruminants. V. Entry rate into the body and incorporation into milk fat of $\beta$-hydroxybutyrate. J. Dairy Sci. 52:633-638.

Peterson, R. G., T. E. Nash, and J. A. Shelford. 1982. Heritabilities and genetic correlations for serum and production traits of lactating Holsteins. J. Dairy Sci. 65:1556-1561.

Pryce, J. E., O. Gonzalez-Recio, G. Nieuwhof, W. J. Wales, M. P. Coffey, B. J. Hayes, and M. E. Goddard. 2015. Hot topic: Definition and implementation of a breeding value for feed efficiency in dairy cows. J. Dairy Sci. 98:7340-7350.

Reist, M., D. Erdin, D. von Euw, K. Tschuemperlin, H. Leuenberger, C. Delavaud, Y. Chilliard, H. M. Hammon, C. Morel, Ch. Philipona, Y. Zbinden, N. Kuenzi, and J. W. Blum. 2003. Concentrate 
feeding strategy in lactating dairy cows: Metabolic and endocrine changes with emphasis on leptin. J. Dairy Sci. 86:1690-1706.

Rius, A. G., S. Kittelmann, K. A. Macdonald, G. C. Waghorn, P. H. Janssen, and E. Sikkema. 2012. Nitrogen metabolism and rumen microbial enumeration in lactating cows with divergent residual feed intake fed high-digestibility pasture. J. Dairy Sci. 95:50245034 .

Savietto, D., D. P. Berry, and N. C. Friggens. 2014. Towards an improved estimation of the biological components of residual feed intake in growing cattle. J. Anim. Sci. 92:467-476.

Silva, J. E. 2001. The multiple contributions of thyroid hormone to heat production. J. Clin. Invest. 108:35-37.

Slebodziński, A. B., E. Brzezinska-Slebodzinska, E. Styczynska, and M. Szejnoga. 1999. Presence of thyroxine deiodinases in mammary gland: Possible modulation of the enzyme-deiodinating activity by somatotropin. Domest. Anim. Endocrinol. 17:161-169.

Vallimont, J. E., C. D. Dechow, J. M. Daubert, M. W. Dekleva, J. W. Blum, C. M. Barlieb, W. Liu, G. A. Varga, A. J. Heinrichs, and C. R. Baumrucker. 2010. Genetic parameters of feed intake, production, body weight, body condition score, and selected type traits of Holstein cows in commercial tie-stall barns. J. Dairy Sci. 93:4892-4901.

Vallimont, J. E., C. D. Dechow, J. M. Daubert, M. W. Dekleva, J. W. Blum, C. M. Barlieb, W. Liu, G. A. Varga, A. J. Heinrichs, and C. R. Baumrucker. 2011. Heritability of gross feed efficiency and associations with yield, intake, residual intake, body weight, and body condition score in 11 commercial Pennsylvania tie stalls. J. Dairy Sci. 94:2108-2113.
Vallimont, J. E., C. D. Dechow, J. M. Daubert, M. W. Dekleva, J. W. Blum, W. Liu, G. A. Varga, A. J. Heinrichs, and C. R. Baumrucker. 2013. Short communication: Feed utilization and its associations with fertility and productive life in 11 commercial Pennsylvania tie-stall herds. J. Dairy Sci. 96:1251-1254.

VanRaden, P. M., C. P. Van Tassell, G. R. Wiggans, T. S. Sonstegard, R. D. Schnabel, J. F. Taylor, and F. S. Schenkel. 2009. Invited Review: Reliability of genomic predictions for North American Holstein bulls. J. Dairy Sci. 92:16-24.

Veerkamp, R. F., B. Beerda, and T. van der Lende. 2003. Effects of genetic selection for milk yield on energy balance, levels of hormones, and metabolites in lactating cattle, and possible links to reduced fertility. Livest. Prod. Sci. 83:257-275.

Wittenburg, D., N. Melzer, L. Willmitzer, J. Lisec, U. Kesting, N. Reinsch, and D. Repsilber. 2013. Milk metabolites and their genetic variability. J. Dairy Sci. 96:2557-2569.

Xi, Y. M., Z. Yang, F. Wu, Z. Y. Han, and G. L. Wang. 2015. Gene expression profiling of hormonal regulation related to the residual feed intake of Holstein cattle. Biochem. Biophys. Res. Commun. 465:19-25.

Zarrin, M., L. De Matteis, M. C. M. B. Vernay, O. Wellnitz, H. A van Dorland, and R. M. Bruckmaier. 2013. Long-term elevation of beta-hydroxybutyrate in dairy cows through infusion: Effects on feed intake, milk production, and metabolism. J. Dairy Sci. 96:2960-2972. 